\title{
Changes of orbital connective tissue after bimatoprost injection. Experimental study in rats
}

\section{Alteração do tecido conjuntivo orbitário após aplicação de bimatoprost: estudo experimental em ratos}

Nilson Lopes da Fonseca Junior' ${ }^{1}$ Giuliana Petri ${ }^{1}$, Juliana Mora Veridiano ${ }^{1}$, José Ricardo Carvalho Lima Rehder ${ }^{1}$

\begin{abstract}
Bimatoprost is commonly used as the drug of first choice in the treatment of primary open-angle glaucoma. Conjunctival hyperemia, eyelash growth, enophthalmos, periocular skin pigmentation, deep lid sulcus and itching eyes have been reported in patients that daily received single dosages during a three month period. The exact mechanism for these adverse effects remains unknown. Objective: to verify alterations, in test animals, of the orbital connective tissue after peribulbar injections of bimatoprost $0.03 \%$ using histological and immune-histochemical analysis. Methods: thirty six male test rats (Rattus norvegicus albinus) were subjected to various periods of periocular injections of bimatoprost $0.03 \%$ in the right eye. All extracted material was submitted to histological, morphometric (diameter, numeric density and density of adipocyte volume) and immune-histochemical analysis to mark the vascular endothelial growth factor $(V E G F)$. These analysis results were then submitted to a descriptive analysis with the help of $R$ software. The significance level used was $5 \%$. For comparison, the model of linear regression with mixed effects was proposed. Results: In the sample studied, the eye sockets that were continuously submitted to bimatoprost had a denser conjunctival tissue around the optic nerve, with numerous capillaries and blood vessels of various sizes and a reduction of quantity, diameter and volume of adipose cells of statistic importance when compared to the contralateral eye socked and the control group. Conclusion: In this study, the following potentially reversible changes of orbital connective tissue were observed in test rats subjected to periocular injection of bimatoprost: 1) reduction of quantity, diameter and volume of orbital adipose cells; 2) local neovascularization; 3) thickening and remodeling of collagen fibers in the orbital cavity
\end{abstract}

Keywords: Antagonists of prostaglandins/adverse effects, Connective tissue/drug effects; Rats

\section{ReSUMO}

O bimatoprost é utilizado comumente como a droga de primeira escolha no tratamento do glaucoma primário de ângulo aberto. Hiperemia conjuntival, crescimento dos cílios, enoftalmia, escurecimento cutâneo periocular, sulco palpebral profundo e prurido ocular têm sido relatados em pacientes que receberam bimatoprost em doses únicas diárias durante cerca de 3 meses. O mecanismo exato para estes efeitos adversos permanece desconhecido. Objetivo: Verificar em animais de experimentação, as alterações do tecido conjuntivo orbitário após injeção retrobulbar de bimatoprost $0,03 \%$. Métodos: Foram utilizados trinta e seis ratos machos (Rattus norvegicus albinus) submetidos a diferentes períodos de injeção retrobulbar de bimatoprost à direita. O material exenterado foi submetido à análise histológica, morfométrica (diâmetro, densidade numérica e densidade de volume dos adipócitos) e imunohistoquímica para marcação do VEGF. Os resultados destas análises foram submetidos à análise descritiva com o auxílio do software R. O nível de significância adotado foi 5\%. Para as comparações foi proposto o modelo de regressão linear com efeitos mistos. Resultados: $\mathrm{Na}$ amostra estudada, as órbitas submetidas a injeções retrobulbares de bimatoprost apresentaram ao redor do nervo óptico tecido conjuntivo mais espesso, com inúmeros capilares e vasos de vários calibres e a redução da quantidade, diâmetro e volume das células adiposas estatisticamente significativo quando comparado à órbita contralateral e ao grupo controle. Conclusão: Neste estudo observaram-se as seguintes alterações potencialmente reversíveis do tecido conjuntivo orbitário nos ratos submetidos à injeção retrobulbar de bimatoprost: 1) redução da quantidade, do diâmetro e do volume das células adiposas orbitárias; 2) neovascularização local; 3) espessamento e remodelamento das fibras de colágeno na cavidade orbitária.

Descritores: Antagonistas de prostaglandina/efeitos adversos, Tecido conjuntivo/ efeitos de drogas; Ratos

${ }^{1}$ Faculdade de Medicina do ABC, Santo André, SP, Brasil.

The authors declare no conflicts of interests.

Recived for publication 17/02/2015 - Accepted for publication 06/06/2016 


\section{INTRODUCTION}

A mong the causes of irreversible blindness, glaucoma is the most common in the world, being the primary openangle chronic glaucoma the most frequent one.(1) Bimatoprost is commonly used as the first-choice drug in the treatment of primary open-angle glaucoma, and it is usually well tolerated ${ }^{(2)}$. Bimatoprost $0.03 \%$ eyedrops is a prostamide with powerful ocular hypotensive action ${ }^{(3)}$. It is a synthetic analogue of prostaglandin F2 $\mathrm{U}$ (PGF2 $\ddot{\mathrm{U}}$ ) (2) which reduces the IOP in humans because it increments the uveoescleral or non-conventional drainage of aqueous humor ${ }^{(4)}$.

Its selectivity copies the effects of prostamide F2alpha, a naturally occurring substance. PGF2 $\ddot{U}$ is synthesized by a route involving $\mathrm{COX}-2$ but not $\mathrm{COX}-1$, suggesting a new route leading to the synthesis of endogenous lipid amides which reduce the intraocular pressure (IOP). Bimatoprost differs from prostaglandins as it does not stimulate the prostanoid receptors, is not mitogenic, does not contract the human uterus, and is electrochemically neutral ${ }^{(5,6)}$

Clinical studies have reported ocular and periocular adverse events in 15 to $45 \%$ of patients receiving daily doses of eyedrops for three months. In decreasing order of incidence, the most adverse effects observed were: conjunctival hyperemia, growth of eyelashes and ocular pruritus ${ }^{2}$. Approximately $3 \%$ of patients discontinued treatment because of adverse events ${ }^{(7)}$.

The orbital and eyelid changes attributed to the use of bimatoprost as deep eyelid crease, enophthalmos and mitigation of dermatochalasis have been reported more frequently in recent years ${ }^{(8,9)}$. The pioneers were Peplinski and Albiani Smith, who related the presence of deep upper eyelid crease and mitigation of unilateral and ipsilateral dermatochalasis to the use of bimatoprost $0.03 \%$ eyedrops in three caucasian patients ${ }^{(8)}$.

Another eyelid adverse effect observed was the increase in the palpebral fissure, which can be caused by Muller muscle stimulation for prostamide, which probably mediates relaxation and contraction of the smooth muscle cell ${ }^{(10)}$. Some authors have noted an improvement of signs considered side effects after discontinuation of medication ${ }^{(10)}$.

Prostaglandins, more specifically PGE1, can induce indirect angiogenesis via the induction of expression of vascular endothelial growth factor (VEGF) ${ }^{(11)}$.

However, all these mechanisms proposed for known adverse effects to bimatoprost and other prostaglandin analogues do not seem to cause a deep eyelid crease. It is postulated that both the contraction or fibrosis of Muller muscle and atrophy of orbital fat may affect the onset of this adverse effect ${ }^{(9)}$, but the exact mechanism remains unknown.

In this study, the aim was to check in rats by histological and immunohistochemical analysis the changes of connective orbital tissue after peribulbar application of bimatoprost $0.03 \%$.

\section{Methods}

We used thirty six male rats (Rattus norvegicus albinos) from the strain Wistar weighing approximately 400 grams, supplied and maintained by the central vivarium at Faculdade de
Medicina do ABC. The animals were divided into eight groups. Some animals were continuously subject to one retrobulbar injection of bimatoprost every week on the right orbit during 4 weeks (Group 1 or G1, $\mathrm{n}=05$ ) 8 weeks (Group 2 or $\mathbf{G 2 ,}, \mathrm{n}=06$ ) and 12 weeks (Group 3 or $\mathbf{G 3}, \mathrm{n}=05$ ). Some animals were subject to one retrobulbar injection of bimatoprost every week on the right orbit during 12 weeks, and were kept without medication for 4 weeks (Group 4 or G4, n=03) 8 weeks (Group 5 or G5, $\mathrm{n}=05$ ) and 12 weeks (Group 6 or G6, $\mathrm{n}=06$. In the Group Control $(\mathbf{C O}, \mathbf{n}=06)$ the animals were subjected to retrobulbar injection of saline solution every week on the right orbit for 4 weeks. These injections had a volume similar to the injections carried out in animals of other study groups.

The amount of bimatoprost injected was $49 \mu \mathrm{g}$, being determined as follows: The medication injected was bimatoprost $0.03 \%$ eyedrops. This eyedrop bottle contains $3 \mathrm{ml}$, and each $\mathrm{ml}$ (41 drops) contains $0.3 \mathrm{mg}$ of bimatoprost. The dosage of this eyedrops is 1 droplet a day, i.e., 7 droplets per week. Therefore, if $1 \mathrm{ml}$ of eyedrops ( 41 drops) contains $0.3 \mathrm{mg}$ of bimatoprost, 1 droplet contains $0.007 \mathrm{mg}$, and 7 droplets contain $0.049 \mathrm{mg}$ or $49 \mu \mathrm{g}$. Based on the study of Woodward et $\mathrm{al}^{(6)}$, this dose was safe for the animals. Woodward et $\mathrm{al}^{(6)}$ used 2 droplets of bimatoprost $0.1 \%$ daily in monkeys weighting $2 \mathrm{~kg}$, and this dose showed traces of metabolic substances in the blood of the animals, ensuring that this dose was not toxic. This dose of 2 daily droplets of bimatoprost $0.1 \%$ is equivalent to 6 droplets per day of bimatoprost $0.3 \%$, i.e., 42 droplets per week in animals weighting $2 \mathrm{~kg}$. This way, we can suggest that for an animal weighting $400 \mathrm{~g}$ a dose of up to 8.4 droplets weekly is not toxic.

For the application of the medication, the animals were anesthetized with a mixture of xylazine $(5 \mathrm{mg} / \mathrm{kg}$ ) and ketamine $(10 \mathrm{mg} / \mathrm{kg})$ applied intraperitoneally ${ }^{(6)}$. After induction of anesthesia, the antisepsis of the eyelids was made with iodized alcohol, and a peribulbar injection of bimatoprost $0.03 \%$ was applied on the right orbit ( $49 \mu \mathrm{g} / \mathrm{orbit} / \mathrm{week})$.

After the study period specified for each group, animals were sacrificed by inhalation of $\mathrm{CO}_{2}$, and then subjected to bilateral orbital exenteration with the aid of a surgical microscope.

All exenterated material was sent for making histologic slides, being discarded the first $100 \mu \mathrm{m}$ of the block since, as noted in the pilot phase of this study, the presence of adipose tissue in that region was maximum for most rats. The slides were subjected to hematoxylin-eosin staining and immunohistochemical study. The descriptive and morphometric histological analyses were performed with hematoxylin-eosin staining, but in the morphometric analysis the estimates of the diameter of the adipocytes (Dv), the numerical density of adipocytes (Nv) and the volume density of adipocytes $(\mathrm{Vv})$ were carried out. The immunohistochemical study was performed to analyze the marking of vascular endothelial growth factor - VEGF (antiVEGF Igb 1 - Abcam, Cambridge, MA, USA).

The morphometric analysis for the estimation of the diameter of the adipocytes (Dv) selected the photomicrographs of each group at $100 \mathrm{X}$ increase. Data was obtained by taking the measure of the diameter of 100 adipocytes by group, chosen at random. Then the average of 100 measurements for each group was calculated. The diameter measurements of adipocytes were made using the tool straight line from the Program Image J Launcher

For the evaluation of a particular cellular component surface density it is required to superimpose crosshair lines to a 
photomicrograph and count the number of intersections between the object surface and the reference lines. This gives us a measure of the surface density of that component, in a certain area unit considered. To estimate the numerical density $(\mathrm{Nv})$ of the adipocytes studied the method proposed by Aherne ${ }^{(12)}$ was used, which is given by the formula:

$$
\mathbf{N v}=\frac{2 \cdot \mathbf{N}_{\mathrm{A}}}{\text { i.d }+2 \mathrm{t}} \text {, where: }
$$

$\mathrm{Nv}=$ numerical density of adipocytes;

$\mathrm{N}_{\mathrm{A}}$ = number of adipocytes per area unit;

$\mathrm{i}=$ number of intersections line/adipocyte divided by the number of adipocytes in the study area;

$\mathrm{d}=$ distance between the lines;

$\mathrm{t}=$ thickness of the cut.

For the evaluation of the adipocyte volume density ( $\mathrm{Vv}$ ) a crosshair of points superimposed on photomicrographs was also needed, and the relation proposed by Weibel was used ${ }^{(13)}$.

$\mathbf{V v}=\mathrm{P} 1 / \mathrm{P}$, where:

$\mathrm{Vv}=$ volume density of a given component;

$\mathrm{P} 1$ = number of incident points on the component studied;

$\mathrm{P}=$ total of incident points on the volume unit

Regarding the statistical analysis, first an exploratory analysis of the data was performed in order to synthesize a series of related values, allowing a global overview of the variation of these values and organizing and describing the data with tables with descriptive measures and graphs ${ }^{(14)}$. The significance used level was $5 \%$.

For comparisons, the linear regression model with mixed effects was proposed. This model is used in the data analysis in which the answers are grouped, i.e., more than one measure for the same individual, and the assumption of independence between observations in the same group is not suitable ${ }^{(14)}$.

\section{Results}

\section{Descriptive histological analysis}

In all groups, the optic nerve and preserved connective layers were observed. The dura mater is presented as a dense modeled connective tissue with large amounts of vessels of various calibers. Around this connective tissue there is little amount of adipose tissue, which is presented as spherical cells, and the cytoplasm seems a peripheral rim, and the nucleus is in the periphery of the cell due to the pressure caused by the lipid droplet located within the cytoplasm.

Groups 1, 2 and 3. As shown in figure 1, the optic nerve and conjunctival layers are preserved, as shown in the ocular orbits on both sides (right and left). The right orbit shows that the connective tissue around the optic nerve seems thicker and with numerous capillaries and vessels of various calibers. In addition, the right orbit shows that the amount of adipose tissue is smaller than on the left orbit (Figure 1). The fibrillar collagen of the connective tissue is colored in pink and with typical organization of non-modeled dense connective tissue.
Groups 4, 5 and 6. In these groups the optic nerve and conjunctive layers are preserved. However, a large amount of adipose tissue is seen around the dense connective tissue (Figure 1).

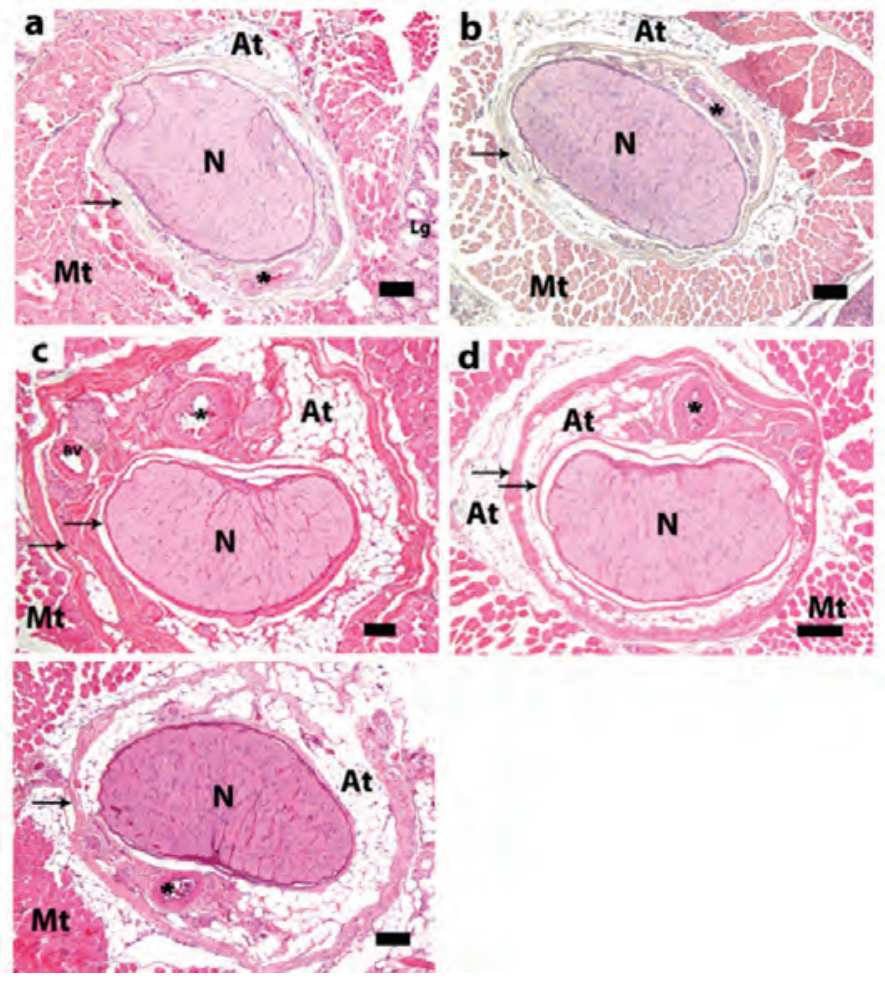

Figure 1: Photomicrography - Rat orbit - 10X increase. HE. a) Animal from Group 2 - right orbit: thickening of the optic nerve sheath and reduction of the volume of the adipose body, compared to the group control. b) Animal from Group 2 - left orbit: thickening of the optic nerve sheath and reduction of the volume of the adipose body, compared to the group control, but at a lower intensity compared to the right orbit in the same group.c) Animal from Group 6 - right orbit: there is a similarity with the findings described in the group control. d) Animal from Group 6 - left orbit: there is a similarity with the findings described in the group control and the right orbit of the same group. e) Group control.

N - Optic nerve, At - adipose tissue, Mt - muscle tissue, SETA Connective tissue or dura mater, ${ }^{*}$ Ophthalmic artery

\section{Morphometric histological analysis \\ Comparative analysis of the adipocyte diameter between the orbits of the same group}

Table 1 shows that when the diameter of adipocytes (day) on the right orbit is compared with the one on the left at the same time, only the groups control ( $\mathrm{CO}$ ) and G6 (animals subjected to the application of bimatoprost for 3 months and discontinuation of medication for 3 months) show differences.

In the control group, the diameter of adipocytes on the right orbit $(\mathrm{RE})$ is greater $(\mathrm{p}<0.01)$ than the one on the left orbit (LE), because the ED (estimated difference) between the right and the left orbits is positive, that is:

day RE CO - day LE CO = positive value 
Table 1

Comparative analysis of adipocytes diameter $(\mu \mathrm{m})$ between the left and right orbits in the same group

\begin{tabular}{llcc}
\hline & Comparisons & ED & p-Value \\
\hline CO & Right - Left & 0.182 & $<0.01$ \\
G1 & Right - Left & -0.001 & 0.99 \\
G2 & Right - Left & 0.027 & 0.99 \\
G3 & Right - Left & -0.052 & 0.28 \\
G4 & Right - Left & -0.030 & 0.99 \\
G5 & Right - Left & -0.077 & 0.06 \\
G6 & Right - Left & -0.076 & $<0.01$ \\
\hline
\end{tabular}

$\mathrm{ED}=$ estimated difference of the adipocyte diameter between the groups ${ }^{1}$

In group 6 , the diameter of adipocytes on the right orbit $(\mathrm{RE})$ is smaller $(\mathrm{p}<0.01)$ than the one on the left orbit $(\mathrm{LE})$, because the ED (estimated difference) between the right and the left orbits is negative, that is:

day RE G6 - day LE G6 = negative value

Comparative analysis of the average values of the diameter of the adipocytes between the group control and the groups subject to orbital application of bimatoprost

Table 2 shows the comparative analysis of the average diameter of the adipocytes of the right (RE) and left (LE) orbits between the group control $(\mathrm{CO})$ and other groups of the study.

The diameter of the adipocytes was smaller $(p<0.01)$ on the right orbit of the animals subjected to the application of bimatoprost for 1, 2 and 3 months (Groups 1, 2 and 3, respectively) when compared to the right orbit of the group control, because the ED (estimated difference) between group control and groups 1,2 and 3 is positive, that is:

day RE CO - day RE (G1, G2 or G3) = positive value

Table 2 also shows that the diameter of the adipocytes was greater $(\mathrm{p}<0.01)$ on the left orbit of the animals subjected to the application of bimatoprost for 3 months and discontinuation of medication for 1, 2, 3 months (Groups 4, 5 and 6, respectively) when compared to the left orbit of the group control, because the ED (estimated difference) between group control and groups 4, 5 and 6 is negative, that is:

day LE CO - day LE(G4, G5 or G6) = negative value

Table 2

Comparative analysis of average diameter values $(\mu \mathrm{m})$ of adipocytes between the groups

\begin{tabular}{lcc|ccc}
\hline \multicolumn{3}{c|}{ Right orbit } & \multicolumn{3}{c}{ Left orbit } \\
\hline Comparisons & ED & p-Value & Comparisons & ED & p-Value \\
\hline CO-G1 & 0.242 & $<0.01$ & CO-G1 & 0.059 & 0.85 \\
CO-G2 & 0.242 & $<0.01$ & CO-G2 & 0.071 & 0.65 \\
CO-G3 & 0.206 & $<0.01$ & CO-G3 & -0.028 & 0.99 \\
CO-G4 & -0.030 & 0.99 & CO-G4 & -0.242 & $<0.01$ \\
CO-G5 & -0.021 & 0.99 & CO-G5 & -0.280 & $<0.01$ \\
CO-G6 & -0.047 & 0.92 & CO-G6 & -0.305 & $<0.01$ \\
& & & & & \\
\hline
\end{tabular}

$\mathrm{ED}=$ estimated difference of the adipocyte diameter between the groups
Comparative analysis of the average values of the diameter of the adipocytes between the groups subject to orbital application of bimatoprost

Table 3 shows that the diameter of the adipocytes was smaller $(\mathrm{p}<0.01)$ on the right orbits of animals subjected to the application of bimatoprost for 1,2 and 3 months (groups 1,2 and 3 , respectively) when compared to the diameter of the adipocytes on the right orbit of animals subjected to the application of bimatoprost for 3 months and with discontinuation of medication by 1, 2 and 3 months (groups 4, 5 and 6, respectively), because the ED (estimated difference) between groups 1,2 and 3 and groups 4, 5 and 6 is negative, that is:

day (G1, G2 or G3) RE - day (G4, G5 or G6) RE = negative value

Table 3 also shows that the diameter of the adipocytes was smaller $(\mathrm{p}<0.01)$ on the left orbits of animals subjected to the application of bimatoprost for 1, 2 and 3 months (groups 1,2 and 3 , respectively) when compared to the diameter of the adipocytes on the left orbit of animals subjected to the application of bimatoprost for 3 months and with discontinuation of medication by 1, 2 and 3 months (groups 4, 5 and 6, respectively), because the ED (estimated difference) between groups 1,2 and 3 and groups 4, 5 and 6 is negative, that is:

day (G1, G2 or G3) LE - day (G4, G5 or G6) LE = negative value

Table 3

Comparative analysis of average diameter values $(\mu \mathrm{m})$ of adipocytes between the groups subjected to bimatoprost

\begin{tabular}{lcc|ccr}
\hline \multicolumn{3}{c|}{ Right Orbit } & \multicolumn{3}{c}{ Left Orbit } \\
\hline Comparisons & ED & p-Value & Comparisons & ED & p-Value \\
\hline G1 - G2 & -0.016 & 0.99 & G1 - G2 & 0.012 & 0.99 \\
G1 - G3 & -0.036 & 0.99 & G1 - G3 & -0.087 & 0.25 \\
G1 - G4 & -0.279 & $<0.01$ & G1 - G4 & -0.301 & $<0.01$ \\
G1 - G5 & -0.289 & $<0.01$ & G1 - G5 & -0.339 & $<0.01$ \\
G1 - G6 & -0.289 & $<0.01$ & G1 - G6 & -0.364 & $<0.01$ \\
G2 - G3 & -0.019 & 0.99 & G2 - G3 & -0.099 & 0.12 \\
G2 - G4 & -0.255 & $<0.01$ & G2 - G4 & -0.313 & $<0.01$ \\
G2 - G5 & -0.247 & $<0.01$ & G2 - G5 & -0.351 & $<0.01$ \\
G2 - G6 & -0.273 & $<0.01$ & G2 - G6 & -0.376 & $<0.01$ \\
G3 - G4 & -0.236 & $<0.01$ & G3 - G4 & -0.214 & $<0.01$ \\
G3 - G5 & -0.228 & $<0.01$ & G3 - G5 & -0.252 & $<0.01$ \\
G3 - G6 & -0.254 & $<0.01$ & G3 - G6 & -0.277 & $<0.01$ \\
G4 - G5 & -0.008 & 0.99 & G4 - G5 & -0.038 & 0.99 \\
G4 - G6 & -0.017 & 0.99 & G4 - G6 & -0.063 & 0.86 \\
G5 - G6 & -0.026 & 0.99 & G5 - G6 & -0.025 & 0.99 \\
\hline
\end{tabular}

$\mathrm{ED}=$ estimativa da diferença do diâmetro do adipócito entre os grupos

Descriptive analysis of the number of adipocytes, average diameter of the adipocytes ( $\mu \mathrm{m})$, and orbital volume percentage filled by adipose tissue in each group

Table 4 shows that there was a reduction in the number of adipocytes in animals continuously subjected to the application of bimatoprost on the right orbit for 1, 2 and 3 months, (groups 1,2 and 3 , respectively) when compared to the group control. 
This numerical reduction was greater on the right orbit (local application of bimatoprost) than on the left one. After the discontinuation of the medication for 1, 2 and 3 months (groups 4,5 and 6, respectively), there was an increase in the number of adipocytes that was numerically similar to the findings in the group control.

Regarding the average diameter of the adipocytes, table 4 shows a reduction of these values when compared to the group control. This reduction was greater in right orbit than on the left one. Also, after the discontinuation of the medication for 1,2 and 3 months (groups 4, 5 and 6, respectively), there was an increase in the average diameter of the adipocytes, numerically similar on the right orbit and greater on the left one when compared to the values in the group control.

Note that the adipose body in animals continuously subjected to bimatoprost on the right orbit for 1,2 and 3 months, (groups 1,2 and 3, respectively) presents a smaller volume in the orbit when compared to the animals in the group control, both on the right and the on the left. After the discontinuation of medication for 1, 2 and 3 months (groups 4, 5 and 6, respectively), the orbital adipose body presented a volume numerically similar to the $\mathrm{CO}$, and a larger volume when compared to the values of the animals that were continuously exposed to the bimatoprost.

\section{Table 4}

Comparative analysis of average number of adipocytes $(\mu \mathrm{m})$ and orbital volume percentage filled by adipose tissue between the groups

\begin{tabular}{lllll}
\hline Group & Orbit & $\mathbf{N}_{\text {AD }}$ & Day & Vol \\
\hline CO & Right & 145.8 & 0.5 & 35 \\
& Left & 185 & 0.33 & 46 \\
G1 & Right & 89 & 0.25 & 26 \\
& Left & 124 & 0.25 & 32 \\
G2 & Right & 72 & 0.27 & 23 \\
& Left & 150 & 0.24 & 36 \\
G3 & Right & 84.56 & 0.28 & 25.2 \\
& Left & 128.67 & 0.34 & 32.6 \\
G4 & Right & 173.95 & 0.52 & 39.4 \\
& Left & 241 & 0.55 & 48.8 \\
G5 & Right & 187.75 & 0.51 & 41.4 \\
& Esq & 189 & 0.58 & 41.6 \\
G6 & Dir & 177.77 & 0.53 & 40 \\
& Esq & 199 & 0,6 & 42 \\
\hline
\end{tabular}

$\mathrm{N}_{\mathrm{AD}}$ = number of adipocytes

Day $=$ average adipocyte diameter

$\mathrm{Vol}=$ orbital volume percentage comprising the adipose body

\section{Immunohistochemical analysis}

Groups 1, 2 and 3. The results obtained in the immunohistochemical study of anti-VEGF reveal that there is a positive staining (brown color) only on the right orbits of the groups treated (Figure 2). In the group control, the staining wasn't very intense, despite being positive.

\section{Groups 4, 5 and 6.}

The immunohistochemical results for VEGF identification show positive staining (brown color), but with less intensity (Figure 2) when compared to that observed in groups 1, 2 and 3.
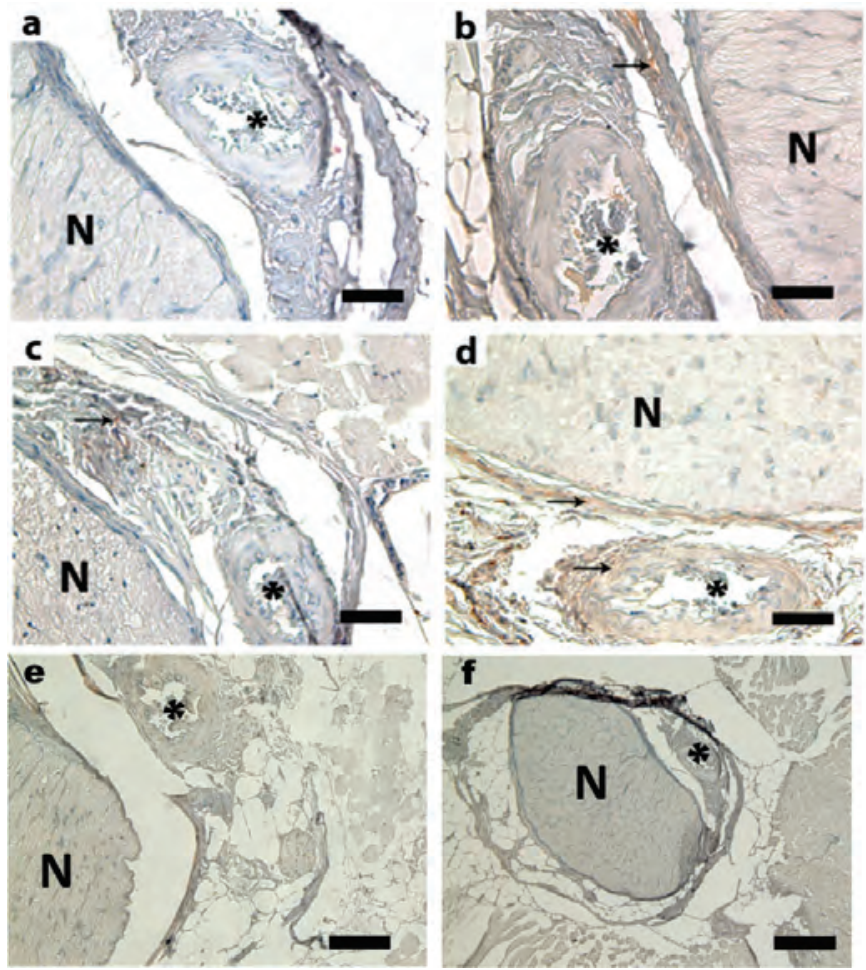

Figure 2: Photomicrography. IH. a) 40X increase - VEGF - group control - left orbit. Absence of new vessels. b) 40X increase - VEGF Group 1 - left orbit. Presence of new vessels c) 40X increase - VEGF - control - right orbit. Absence of new vessels. d) 40X increase - VEGF - Group 1 - right orbit. Presence of new vessels. b) 40X increase VEGF - Group 5 - left orbit. Absence of new vessels. f) 40X increase - VEGF - Group 5 - right orbit. Absence of new vessels

N - Optic nerve, SETA - Connective tissue or dura mater, *Ophthalmic artery

\section{Discussion}

This study provides a description of histological and immunohistochemical changes of the orbital connective tissue after retrobulbar injection of bimatoprost $0.03 \%$. The literature describes only the adverse clinical findings to the use of bimatoprost $0.03 \%$ eyedrops in glaucoma patients. Peplinski and Smith reported unilateral and ipsilateral deep upper eyelid creases $^{(13)}$. Filippopoulos et al. described upper deep eyelid creases, apparent enophthalmos and attenuation of dermatochalasis ${ }^{(15)}$. Based mainly on the pharmacological properties of bimatoprost, the hypothesis of these eyelid and orbital changes were resulting from the reduction of preaponeurotic and orbital fat was created ${ }^{(13,16,17)}$. Although there is a slight difference in the orbital anatomy and physiology among species, the knowledge gained in animal studies can assist in research in humans.

The rat (Rattus norvegicus albinus) from the stain Wistar were chosen for this study due to its size, ease of handling, availability, number of animals necessary for the comparative study, orbital and eyelid human-like anatomy and physiology ${ }^{(18,19)}$. The choice for adult animals was based on the need to avoid an increase in the orbital cavity and its content during the study, especially in animals participating in the study for 24 weeks (Group 6). Only males were used for standardization of the groups. 
The number of animals participating in this study was defined by Comitê de Ética em Experimentação Animal (CEEA) of FMABC, being allowed the minimum for the development of the study and statistical analysis.

The animals were divided into 7 groups of 6 animals, totaling 42 animals. There were 6 deaths during the follow-up period of the study, distributed as follows: G1 (1 death), G3 (1 death), G4 (3 deaths), G5 (1 death).

Animals in groups G1, G2 and G3 were exposed to unilateral retrobulbar injection (right orbit) of bimatoprost $0.03 \%$ every week for 4,8 and 12 weeks, respectively. The exposure period was thus defined, as the literature reports that the onset of adverse effects in glaucoma patients is observed mainly 3 months after the start of the use of bimatoprost $0.03 \%$ eyedrops ${ }^{(13-15)}$. The unilateral retrobulbar injection allows determining if the adverse effects are local or systemic.

After the maximum period of exposure to bimatoprost $0.03 \%$, the animals of groups G4, G5 and G6 were sacrificed after 4, 8 and 12 weeks without medication, respectively. The objective of the analysis of these groups was to observe the disappearance of changes in the orbital connective tissue after discontinuation of bimatoprost $0.03 \%$, and the time required for this reversal. Some authors report the improvement of the signs after the discontinuation of medication $^{(15)}$.

The animals on G7 (group control) were submitted to unilateral retrobulbar injection (right orbit) of saline solution every week for 4 weeks in order to exclude possible changes of orbital changes triggered by trauma orbit trauma-related inflammatory processes (retrocular injection).

The route of administration of bimatoprost $0.03 \%$ chosen for this study was the retrobulbar injection, which ensures that the orbital tissue had been exposed to the medication dose during the recommended period for each group. The dose used for each injection was equivalent to the weekly dose of bimatoprost $0.03 \%$ recommended for the treatment of glaucoma (7 droplets $=49 \mathrm{ig}$ ).

The present study showed a reduction of the diameter and the number of adipocytes in the orbits continuously subjected to weekly injections of bimatoprost $0.03 \%$ for 30,60 and 90 days (Groups 1, 2 and 3, respectively) compared to the group control. This result suggests that bimatoprost reduces the amount and volume of adipose cells. Choi et al. concluded that bimatoprost inhibits both the differentiation of pre-adipocytes and intracellular lipid accumulation $^{(16)}$.According to Kim, prostaglandin analogues present an inhibitory event especially in the late stage of adipocyte differentiation ${ }^{(17)}$.

A reduction in the diameter and the number of adipocytes in the right orbit of the animals in Groups 1,2 and 3 was also observed when compared to the right orbit of the animals in Groups 4, 5 and 6 (animals treated continuously with weekly injections of bimatoprost $0.03 \%$ for 90 days, followed by discontinuation of the medication for 30,60 and 90 days, respectively). These results suggest that the discontinuation of bimatoprost $0.03 \%$ for 30 days is enough to revert its effect on the adipose tissue.

The reversible effect of bimatoprost is reported in the literature. Yam et $\mathrm{l}^{(10)}$ described a bilateral deepening of the upper eyelid crease in an Asian patient who used bimatoprost $0.03 \%$ daily for three months, being observed the improvement of signs four weeks after discontinuation of the medication. Filippopoulos et al. ${ }^{(15)}$ observed full or partial attenuation of the upper eyelid deep creases and enophthalmos in chronic users of bimatoprost $0.03 \%$ after three to six months of discontinuation of bimatoprost.

There was no statistically significant difference between the diameter of adipocytes in the left and right orbits in groups 1,2 and 3 , nor in groups 4,5 and 6 . These results demonstrate a similarity in the adipocyte diameter between the right and left orbits in animals of the same group, and suggest a systemic and reversible effect of orbital injection of bimatoprost, since the injection was unilateral (right orbit). A study in monkeys ${ }^{(10)}$ showed that the systemic administration of bimatropost causes earlier adverse effects, showing the presence of a prominent periorbital crease and an increase in palpebral fissure with the intravenous administration of bimatoprost for 17 weeks. The same signals were observed in most monkeys studied 6 months after the onset of bimatoprost eyedrops use in doses of $0.03 \%$ twice a day or $0.1 \%$ once a day Pharmacokinetic studies $^{(9)}$ in monkeys have shown that a single instillation of bimatoprost $0.1 \%$ eyedrop had a concentration of bimatoprost in the eyelid two thousand times higher than in the aqueous humor, and 16 times higher in the iris and ciliary body, which indicates significant periorbital absorption of the medication and justifies the local adverse effects.in monkeys have shown that in a single instillation of $0.1 \%$ bimatoprost eye drop was observed two thousand times higher concentration of bimatoprost eyelid than in the aqueous humor, and 16 times higher in the iris and ciliary body, which indicates significant periorbital absorption of medication, justifying the local adverse effects.

The diameter of the adipocytes in the right orbit of group control (orbit subjected to saline solution injection every week for 30 days) was higher when compared to the left orbit of animals of the same group, and to the left and right orbits of groups 1,2 and 3 . On the other hand, the diameter of the adipocytes of the right orbit the CO was similar to the findings of the right and left orbits of groups 4,5 and 6 . These findings suggest that: 1 ) the orbital trauma and/or saline solution can be a stimulus to increase the diameter of the adipocytes, and that bimatoprost can be responsible for the reduction of this diameter and the number of fat cells; 2) after discontinuation of bimatoprost there was a compensatory stimulus to increase the diameter and the number of fat cells.

Despite the volumetric reduction of adipose bodies and numeric reduction of adipocytes, a significant increase of vessels and capillaries (neovascularization) and a thickening and remodeling of collagen fibers were observed in animals of groups 1, 2 and 3 in relation to the control group. No new vessels or remodeling and thickening of collagen fibers were observed in groups 4, 5 and 6 . These findings suggest that bimatoprost changes not only the adipose tissue, but also other connective tissue components, and this adverse effect is also reversible.

The description of the prostaglandin (PG) as a promoter of neovascularization is reported in the literature, especially the subtype $\mathrm{PGE}_{1}^{(11)}$. This is one of the substances used to promote therapeutic angiogenesis. It is a vasodilator substance and inhibitor of platelet aggregation. It also shows activity in the activation of fibrinolysis, modulation of cellular proliferation, fibrogenesis, hemorheological activity on the erythrocyte, inhibition and activation of neutrophils, and also improvement of oxygen and glucose utilization by tissues ${ }^{(18)}$.

In addition to these effects, there is evidence that $\mathrm{PGE}_{1}$ stimulates angiogenesis in myocardial ischemia situations ${ }^{(18)}$. Angiogenesis is modulated by growth factors that are located in endothelial cells and extracellular matrix ${ }^{(18-20)}$. 
VEGF is associated to the onset of the process of vascular neoformation, and is considered a reliable marker of the process ${ }^{(20)}$. In the present study, the immunohistochemical analysis demonstrated positivity of anti-VEGF antibody only in the right orbits of the groups treated with bimatoprost. The presence of neovascularization and increased vascularity can contribute to reducing local adipose body due to the increase of temperature, similar to what happens in orbital varices ${ }^{(21)}$. There are no studies in the literature correlating bimatoprost to the onset of ocular or periocular neovascularization. Scherer, in 2006, found no correlation between the chronic use of bimatoprost eyedrops and the appearance of choroidal neovascular membrane in patients with PCOAG and ARMD ${ }^{(22)}$.

Changes in collagen fibers arising from the use of PG are reported in the literature and differ depending on the type of PG In a study conducted in rats, electron microscopy revealed structural changes of the skin of the epidermal and fibroblast cells after administration of PG-E, including an increase in polyribosomes, endoplasmic reticulum, keratohyalin beads and dilation of intercellular spaces; whereas PGF2alpha induced an advanced cytolysis and cell disintegration. The scanning electron microscopy showed hypertrophied collagen fibers in rats treated with PGE. However, a disruption and disintegration of the collagen fiber occurred in mice treated with PG-F2alpha. These results demonstrate that prostaglandins are potent regulators of epidermal cell structure and metabolism, as well as for the synthesis of collagen ${ }^{(11)}$. Another study conducted in rabbits showed that repeated exposure of the Achilles tendon to the PG-E2 can cause a reduction in collagen type $\mathrm{I}$, an increase in collagen type III, a reduction in the density unit of collagen fibers, and a reduction in the diameter of collagen fibers, which would be related to a tendinopathy ${ }^{(11)}$.

The eyes of rabbits treated with eyedrops of analogue of PGF2alfa showed a diffuse and moderate conjunctival inflammatory infiltrate, but without changes in conjunctival epithelial thickness or greater density of subconjuntival collagen ${ }^{(23)}$. The present study showed a thickening of the collagen fibers of the orbital cavity in the groups receiving bimatoprost.

Literature says that bimatoprost differs from prostaglandins, as it does not stimulate prostanoid receptors, is not mitogenic, does not contract the human womb, and is electrochemically neutral ${ }^{(7-9)}$. However, this study showed the presence of new vessels, reducing the diameter and number of adipocytes, in addition to changing the fibers of the orbital connective tissue during the administration of bimatoprost, suggesting an activation of prostanoid receptors.

The adverse effects of bimatoprost observed in this study were consistent with the retrobulbar application of medication, but we cannot consider that the same changes will be observed if the medication is administered in the form of eyedrops. This way, new researches should be conducted to show the possible changes of orbital connective tissue after continuous instillation of bimatoprost $0.03 \%$ eyedrops and allow the comparison to the results of this study.

\section{CONCLUSION}

This study showed the following potentially reversible changes of the orbital connective tissue in rats subjected to retrobulbar injection of bimatoprost: reduction of quantity, diameter and volume of the orbital adipose cells; local neovascularization; and thickening and remodeling of collagen fibers in the orbital cavity.

\section{ReFERENCES}

1. Salai AF, Souza TT, Netto, AA; Oliveira, LS; Shimono, CT, Cunha, R Dal lOglio da. Epidemiological profile of patients with glaucoma sent to HU-UFSC ophthalmology service. ACM Arq Catarin Med. 2011;40(3):37-42.

2. Parrish RK, Palmberg P, Sheu WP. A comparison of latanoprost, bimatoprost, and travoprost in patients with elevated intraocular pressure: a 12-week, randomized, masked-evaluator multicenter study. Am J Ophthalmol. 2003;135(5):688-703.

3. Cantor LB, WuDunn D, Cortes A, Hoop J, Knotts S. Ocular hypotensive efficacy of bimatoprost $0.03 \%$ and travoprost $0.004 \%$ in patients with glaucoma or ocular hypertension. Surv Ophthalmol. 2004;49 Suppl 1:S12-8.

4. Brubaker RF. Mechanism of action of bimatoprost (Lumigan). Surv Ophthalmol. 2001;45 Suppl 4:S347-51.

5. Easthope SE, Perry CM. Topical bimatoprost: a review of its use in open-angle glaucoma and ocular hypertension. Drugs Aging. 2002;19(3):231-248.

6. Woodward DF, Krauss AH, Chen J et al. Pharmacological characterization of a novel antiglaucoma agent, Bimatoprost (AGN 192024). J Pharmacol Exp Ther. 2003;305(2):772-85.

7. Vogel R, Strahlman E, Rittenhouse KD. Adverse events associated with commonly used glaucoma drugs. Int Ophthalmol Clin. 1999;39(2):107-24.

8. Peplinski LS, Albiani Smith K. Deepening of lid sulcus from topical bimatoprost therapy. Optom Vis Sci. 2004;81(8):574-577.

9. Park J, Cho HK, Moon JI. Changes to upper eyelid orbital fat from use of topical bimatoprost, travoprost, and latanoprost. Jpn J Ophthalmol. 2011;55(1):22-27.

10. Yam JC, Yuen NS, Chan CW. Bilateral deepening of upper lid sulcus from topical bimatoprost therapy. J Ocul Pharmacol Ther. 2009;25(5):471-472.

11. Mehrabi MR, Serbecic N, Tamaddon F, Pacher R, Horvath R, Mall G, Glogar HD.. Clinical benefit of prostaglandin E1-treatment of patients with ischemic heart disease: stimulation of therapeutic angiogenesis in vital and infarcted myocardium. Biomed Pharmacother. 2003;57(3-4):173-8.

12. Aherne W, Dunnil MS. Morphometry. London: Edward Arnold; 1982.

13. Weibel ER. Stereological principles for morphometry in electron microscopic cytology. Int Rev Cytol. 1969;26:235-302.

14. SCHALL R. Estimation in generalized linear models with random effects. Biometrika. 1991;78(4):719-27.

15. Filippopoulos T, Paula JS, Torun N, Hatton MP, Pasquale LR, Grosskreutz CL. Periorbital changes associated with topical bimatoprost. Ophthal Plast Reconstr Surg. 2008;24(4):302-307.

16. Choi HY, Lee JE, Lee JW, Park HJ, Lee JE, Jung JH. In vitro study of antiadipogenic profile of latanoprost, travoprost, bimatoprost, and tafluprost in human orbital preadiopocytes. J Ocul Pharmacol Ther. 2012;28(2):146-52.

17. Kim JW. Topical prostaglandin analogue drugs inhibit adipocyte differentiation. Korean J Ophthalmol. 2014;28(3):257-264.

18. Li H, Tang K, Deng Y, Xie M, Chang D, Tao X, Xu J. [Effects of exogenous prostaglandin E2 on collagen content of Achilles tendon of rabbits in vivo]. Zhongguo Xiu Fu Chong Jian Wai Ke Za Zhi. 2012;26(3):352-8. Chinese.

19. Lupulescu AP. Cytologic and metabolic effects of prostaglandins on rat skin. J Invest Dermatol. 1977;68(3):138-145. 
20. Ito WD, Arras M, Scholz D, Winkler B, Htun P, Schaper W. Angiogenesis but not collateral growth is associated with ischemia after femoral artery occlusion. Am J Physiol. 1997;273(3 Pt 2):H1255-65.

21. Smith RJ, Balbo NS, Lahoz Ibaceta MJ. [Enophthalmos secondary to an orbital varix]. Medicina (B Aires). 2014;74(2):127-9. Spanish.

22. Scherer WJ. Effect of topical prostaglandin analog use on outcome following selective laser trabeculoplasty. J Ocul Pharmacol Ther. 2007;23(5):503-12.
23. Serrero G, Lepak NM. Prostaglandin F2alpha receptor (FP receptor) agonists are potent adipose differentiation inhibitors for primary culture of adipocyte precursors in defined medium. Biochem Biophys Res Commun. 1997;233(1):200-2.

\section{Corresponding author:}

Nilson Lopes da Fonseca Junior

E-mail: lopesdafonseca@uol.com.br 